\title{
Why Does Testosterone Influence Morphology, Behaviour and Physiology?
}

\author{
Matthew R. Evans* \\ Centre for Ecology and Conservation, School of Biosciences, University of Exeter Cornwall Campus, Penryn, Cornwall, \\ TR10 9EZ, UK
}

\begin{abstract}
Several decades of research have produced a large number of studies that examine the effects of hormones on physiology, behaviour and morphology. In the last fifteen years there has been considerable interest from evolutionary biologists on the impact of hormones, especially testosterone, on aspects of physiology in particular immune function. Interestingly, especially given the recent attention from evolutionary biologists, the primary focus has been on determining the existence of links between hormones and other aspects of physiology or behaviour, with an emphasis on the understanding of mechanism. Typically though evolutionary biology focuses not on mechanism but on function - i.e. the evolutionary explanation for why a given trait or relationship between traits exists. Evolutionary biologists would expect that if two parts of an organism's physiology were both affected by a hormone then there should be some adaptive reason why such a link exists. The fact that a hormone simultaneously influences aspects of physiology, behaviour and morphology suggests that individuals linking these traits typically benefit in someway from doing so. This paper attempts to provide some functional explanations for such links and proposes that testosterone may be the hormone that tips animals between 'hare-like' and 'tortoise-like' life-history strategies, with testosterone pushing individuals towards 'hare-like' strategies. If links between physiological, behavioural and morphological traits exist because they benefit the organisms concerned, then we might expect different species with different ecologies to arrive at different adaptive solutions. The lack of consistency between the results of similar studies in different taxa may be informing us that different optimal strategies are arrived at by different species.
\end{abstract}

Keywords: Hormones, immune function, endocrinology, natural selection, behaviour, morphology, functional explanations.

Research on the roles played in the bodies of animals by neuro-endocrine hormones has a long history, stretching back at least 150 years in Europe and arguably much longer in China [19]. The early work was conducted by physiologists primarily interested in the mechanisms by which hormones produce effects on the body's organs, what type of molecules hormones are, and under what conditions they are secreted. For the last fifteen years evolutionary biologists have been paying increasing attention to the roles played by neuro-endocrine hormones. The main trigger for this was to determine whether interactions between the neuro-endocrine system, the immune system, morphology and behaviour could provide a mechanism that might control the honest development of ornamental traits [21]. Folstad and Karter (1992) hypothesised that testosterone acted to suppress immune function whilst simultaneously facilitating the development of ornamental traits. The stimulus given to the field by this paper has resulted in particular attention being paid to the roles played by testosterone - the hormone that is believed to be linked to masculinisation in many vertebrate taxa [23].

Studies that have tested Folstad and Karter's immunocompetence handicap hypothesis have included both experimental manipulations of testosterone and correlative studies.

*Address correspondence to this author at the Centre for Ecology and Conservation, School of Biosciences, University of Exeter Cornwall Campus, Penryn, Cornwall, TR10 9EZ, UK; Tel: +44 1326 371724; E-mail: m.r.evans@exeter.ac.uk
There have been measurements of various aspects of immune function and parasite loads as well as examinations of various morphological traits including known sexual signals and some putative sexual signals. This work has all focussed on whether patterns can be found linking variation in hormone titres with variation in immune function, parasite load and morphology. The results of these studies are at best equivocal. When the work examining the relationship between testosterone and immune function was reviewed [24] the conclusion was that no significant effect of testosterone on immune function could be detected in the studies that had been published in the ten years after the publication of the immuno-competence handicap hypothesis [21].

The immuno-competence handicap hypothesis (Folstad and Karter 1992) requires that testosterone has at least two simultaneous effects - on immune function and morphology. This, in Folstad and Karter's model, is what maintains the honesty of signalling. This raises two questions: 'why does testosterone inevitably suppress immune function?' and 'what is it about the formation of a large ornament that necessitates the involvement of testosterone?' The first of these questions was identified after the publication of Folstad and Karter's paper and there are, to my knowledge, two attempts to answer the question "why is testosterone immunosuppressive?' The first proposed that testosterone suppressed the immune system so that resources could be strategically re-allocated to other functions like sexual signalling [25]; the second suggested that testosterone suppresses immune function in order to protect sperm (the production of which is 


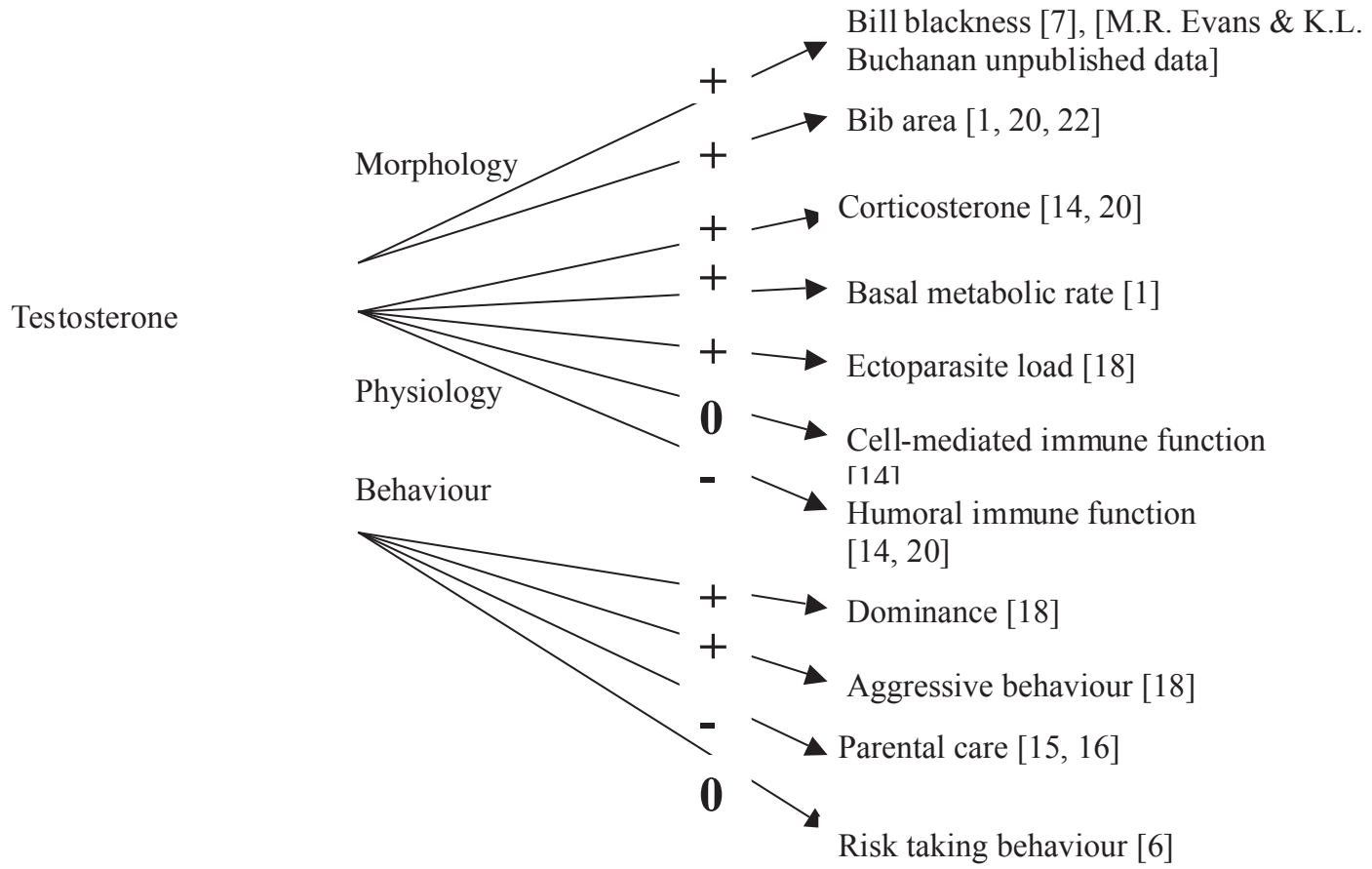

Fig. (1). Summary of the effects of testosterone on house sparrow physiology, morphology and behaviour.

regulated by testosterone) from attack by the male's own immune system [26]. Both Wedekind and Folstad [25] and Hillgarth et al. [26] provide potentially good proximal answers to the question "why is testosterone immunosuppressive?' but leave the second question 'what is it about the formation of a sexual signal that necessitates the involvement of testosterone?' unaddressed. The other prediction made by Folstad and Karter is that testosterone somehow links variation in immune function to variation in suppression of immune function, such that males with large sexual signals inevitably have an immune system functioning at a lower level than it might otherwise.

An examination of the literature beyond that concerned with sexual signalling reveals that testosterone has been implicated in influencing the expression of a variety of behavioural and physiological traits. The most widely known of these is that raising testosterone titre typically increases aggressive behaviour [27] but there are many others; to illustrate this I have attempted to summarise work on one species - the house sparrow (Passer domesticus) in Fig. (1). As can be seen testosterone apparently influences a diverse range of traits from parental care to aggressiveness and from basal metabolic rate to bill colour. This evidence compounds the problem outlined above - "why should testosterone titres influence variation in so many different aspects of an animal's morphology, behaviour and physiology?' if testosterone does influence these (and maybe more) elements of an animal's biology why is it desirable to link them together in this manner?

In 1963, Tinbergen suggested that there were four ways in which the question why could be answered in ethology he suggested that there could be answers at the phylogenetic, developmental, mechanistic and functional levels [28]. Therefore, it would be possible to answer the question 'why does testosterone influence these aspects of biology?' or the question 'why should an animal link these aspects of biology together' in any one of these four ways.

Roberts et al. [24] suggested some mechanistic solutions to the question - why might aspects of physiology be linked by testosterone. These authors suggested that testosterone and corticosterone may covary due to the fact that both hormones bind to corticosterone binding globulin (CBG) [2931]. Individuals with high testosterone titres would have a greater number of their CBG binding sites occupied by testosterone. This should mean that corticosterone titres would rise as less of the corticosterone produced would be bound onto CBG. The converse could also apply, resulting in individuals with low testosterone titres having more of their CBG binding sites free to take up corticosterone thus lowering blood titres of the hormone. An explanation at the mechanistic level for the effect of testosterone on bib size in house sparrows could be that testosterone facilitates the production of melanin from tyrosine through the action of tyrosinase. An alternative mechanism would be that corticosterone reduces luteinising hormone production by the hypothalamus-pituitary complex (this is probably the mechanism by which raised corticosterone reduces reproductive activity)[32]. If luteinising hormone production is impaired then there will be a direct effect on testosterone production by the gonads.

However, evolutionary biology is concerned with providing ultimate rather than proximal explanations; i.e. explanations about adaptation rather than mechanism. The central paradigm of evolutionary biology is that any observed trait should be optimally designed for its function. Although this idea can obviously be taken too far, and in particular there may be constraints that prevent optimality [33], the basic view would be that a trait should have a function and is the best solution to fulfil that function. In the context of the work on testosterone, this raises the question 'why is testosterone 
linked to so many different aspects of an animal's biology?' An adaptationist would suggest that this occurs for a reason - there should be some advantage that accrues to individuals that link aspects of their biology together over individuals that do not. If this was not so then the link should not exist. A less extreme adaptationist view would be that in the very least such a link should be neutral, if there was a cost to having these processes linked then the link should be broken by natural selection. If one or more of the effects of a hormone were deleterious one would expect selection to break this link as the animal would have greater fitness if the deleterious effect was removed. The only argument for a deleterious link still existing would be if there has been insufficient time for selection to produce the required change or insufficient variation on which selection might operate. While both these explanations are valid it seems reasonable to expect that individuals linking various aspects of their biology should typically benefit from so doing.

At this functional level the original question then remains - what is the adaptive value in linking different aspects of physiology, behaviour and morphology? Functional explanations exist for the actions of some hormones, the most obvious of which is probably the role of adrenaline in the 'fight or flight' response - an extremely short-term response to sudden threats from the environment. One of the most wellworked and evidenced functional explanations is that for the glucocorticosteroids. In a seminal paper, Wingfield et al. (1998) suggest a functional explanation for the role of these hormones (in birds primarily corticosterone) as the mediators of an emergency life history stage [34]. Their hypothesis is that animals require a response to environmental perturbations (i.e. relatively short-lived, unpredictable events that challenge the animal's current activities). These environmental stresses are sufficiently severe to jeopardise an animal's survival unless emergency action is taken. Wingfield et al. [34] suggest that glucocorticosteroids are released in response to such environmental stresses and trigger a series of behavioural responses that favour short-term survival over activities with longer-term benefits such as breeding. Therefore we see corticosterone in birds suppressing breeding activity, promoting refuge seeking behaviours or movement away from the stressor, down regulating the immune system, increasing foraging behaviour, increasing mobilisation of food reserves [34]. Two suggestions have been made to explain why corticosterone suppresses immune function; one is that during a stress response, expensive immune defence is sacrificed in order to divert the resources allocated to combating disease into other activities that may have a larger impact on short-term survival of the stress e.g. flight away from the source of stress. The second explanation for corticosterone mediated immune suppression is that it reduces the risks of auto-immune problems [35]. We also see that while these changes might be adaptive in the short-term, chronic exposure to corticosterone can be deleterious as for example long-term immuno-suppression is likely to be undesirable. Wingfield et al. [34] suggest that animals can move into an emergency life history stage at any time of the year and that corticosterone will over-ride other hormones to produce such a stage irrespective of other activities. To use the terminology of the current paper corticosterone links immune function, reproductive behaviour, foraging behaviour, social behaviour and locomotion and Wingfield et al., emergency life history stage hypothesis provides us with an adaptive, functional explanation for these linkages. Fig. (2) present summaries for house sparrows and zebra finches (Taeniopygia guttata) of the morphological, behavioural and physiological effects of corticosterone.

When considering the functional role of testosterone, the most widely cited model is the challenge hypothesis [36]. This hypothesis suggests that there are three levels of testosterone - a basal level representative of the non-breeding season produced by the background secretion of the Leydig cells, during the breeding season males move to a higher equilibrium level which allows spermatogenesis to occur, males reach the third and highest level as a result of social challenges. It is this high third level that relates to behaviour - primarily aggressive behaviour in males. This hypothesis is very useful and has been tested in several systems many of which show the predicted pattern. Wingfield et al. (1990) suggest that the reason why males do not maintain the highest possible levels at all times during the breeding season is due to the fact that testosterone inhibits parental care and that breeding season testosterone titres are the result of a tradeoff between the need to express aggressive behaviour and the degree to which male parental care is needed for successful breeding. However, recent work has suggested that in some species male parental care is insensitive to testosterone titres [37-39] which suggests that selection may be able to break the link between testosterone and parental care. Wingfield et al.'s challenge hypothesis is a functional explanation for the changes in testosterone titre between seasons and between individuals, it does not explain the fact that so many different aspects of an animal's biology appear to be influenced by this one hormone.

\section{A CASE STUDY: THE HOUSE SPARROW}

The black bib of a male house sparrow plays roles in mediating male-male competition over resources [40,41] and possibly in mate choice [42]. Experiments have shown that testosterone appears to influence the size of this signal [1, $20,22]$. Signalling theory suggests that, at equilibrium, signals should be honest reflections of some quality [43]. Therefore, we would expect that individuals possessing large signals of ability to compete over resources should genuinely have high levels of ability to compete over resources. Thus, a male house sparrow with a large bib should also have a high ability or willingness to compete for resources. Poiani et al. [18] demonstrated that in house sparrows, as in many species, high levels of testosterone result in greater aggressive behaviour, which leads to higher dominance status. Therefore, by simultaneously influencing bib size and aggressiveness, testosterone provides the link that maintains the information content of the bib signal. This results in individuals with large bibs having high levels of aggressive behaviour and greater dominance, while individuals with smaller bibs have lower levels of aggressive behaviour and lower dominance.

If an individual needs to maintain high levels of aggressive behaviour it would need to react appropriately to any challenge whenever it was challenged, it may therefore need to mobilise its physiological processes rapidly. Male house sparrows with experimentally raised testosterone titres had significantly higher basal metabolic rate than birds with low 


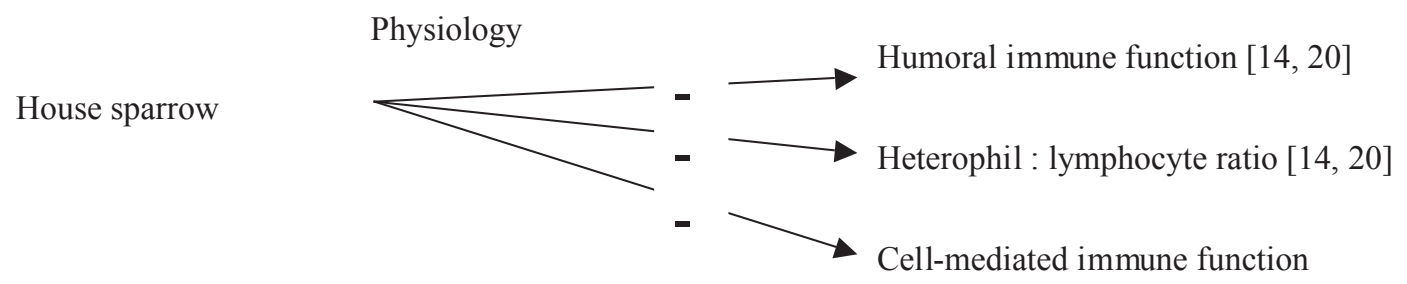

[4]
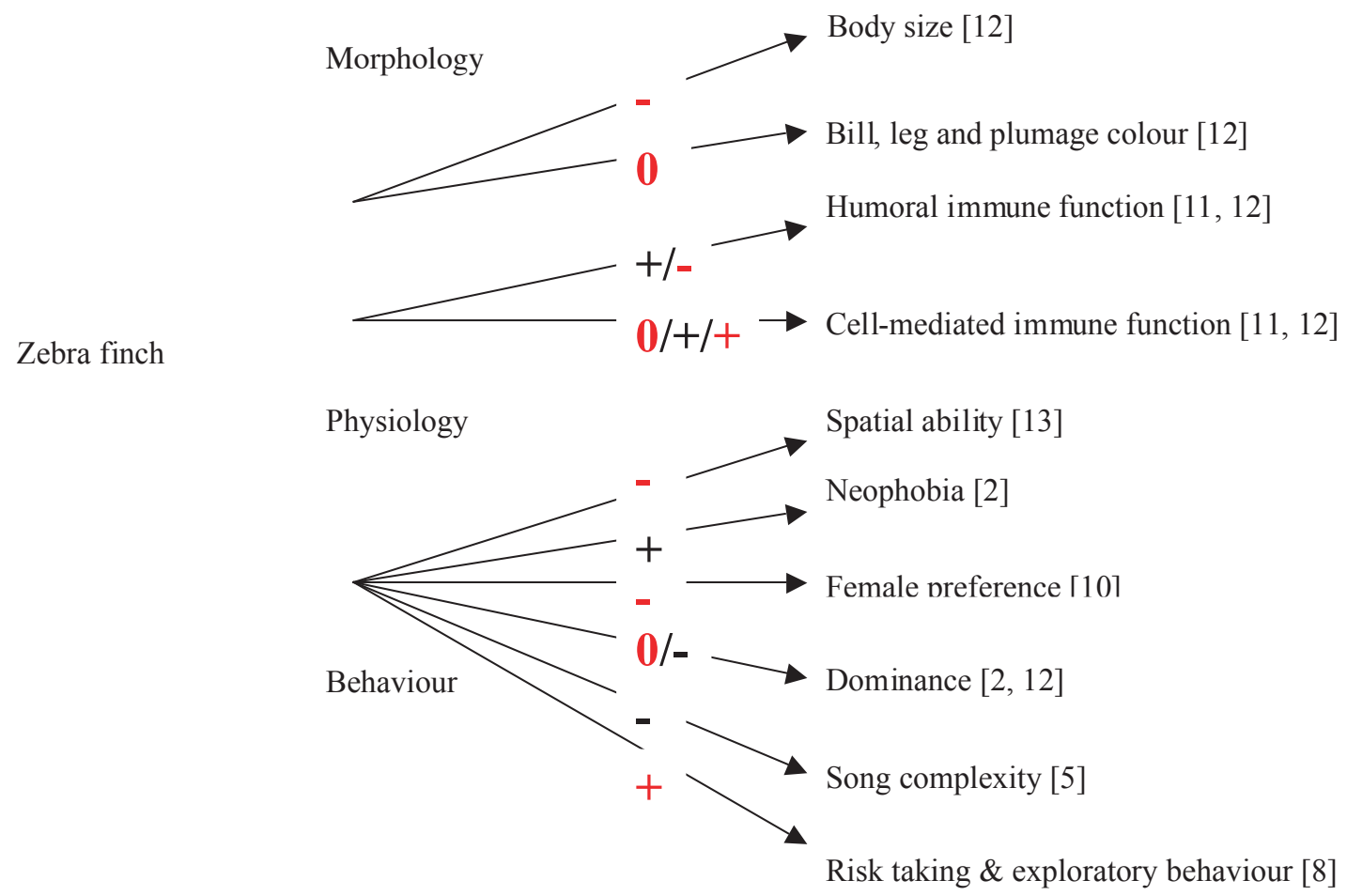

Fig. (2). Summary of the effects of corticosterone on house sparrow and zebra finch physiology, morphology and behaviour (red - effects based on selection, black - effects produced by manipulation).

testosterone titres [1]. Basal metabolic rate is the background level of metabolism - and is measured when the bird is inactive and resting. Individuals with a high basal metabolic rate presumably have a physiology that is operating at a faster rate - or at least uses more energy than individuals with low metabolic rates. At least potentially a high metabolic rate may mean that a challenged individual can respond more rapidly or to a higher level, this may be advantageous for an individual that has adopted an aggressive life history.

In house sparrows, testosterone appears to correlate with corticosterone [14]. Corticosterone is involved in mediating the 'stress response', it is released in response to various stressors $[34,44]$. Its physiological role seems to be to mobilise energy stores, shutdown digestive processes and increase peripheral blood supply $[45,46]$. In addition it reduces reproductive activity whilst increasing dispersal and foraging behaviours $[34,46]$. In summary corticosterone acts to suppress activities that are concerned with long-term survival and reproduction in favour of those concerned with shortterm survival. Returning to the functional question - why would it benefit an aggressive individual with high levels of testosterone and a high metabolic rate to also have high levels of plasma corticosterone? One hypothesis might be that birds with heightened levels of aggression are adopting a life history strategy that is geared towards short-term success - a more 'r-selected' strategy. If this was the case such birds might benefit from an elevation of those aspects of physiology that are geared towards short-term survival rather than long-term survival, this would be the same set of activities that are elevated by corticosterone during a response to stress. This hypothesis would also fit with the observation that birds with elevated testosterone reduce parental care activities [15]. If high testosterone birds were adopting a fast life-history strategy they might benefit from investment in maximising offspring numbers rather than offspring quality, so they would gain by reducing parental care whilst increasing the probability of gaining other mates. Under this hypothesis, birds with low levels of testosterone would be expected to adopt slower life-history strategies - investing in long term survival and reproduction and maximising offspring quality through investment in high levels of parental care to individual offspring. An alternative hypothesis is that high quality individuals, which might have intrinsically more efficient physiological processes (e.g. with more efficient digestion or highly efficient immune function) could strategically down regulate these processes in order to channel the 


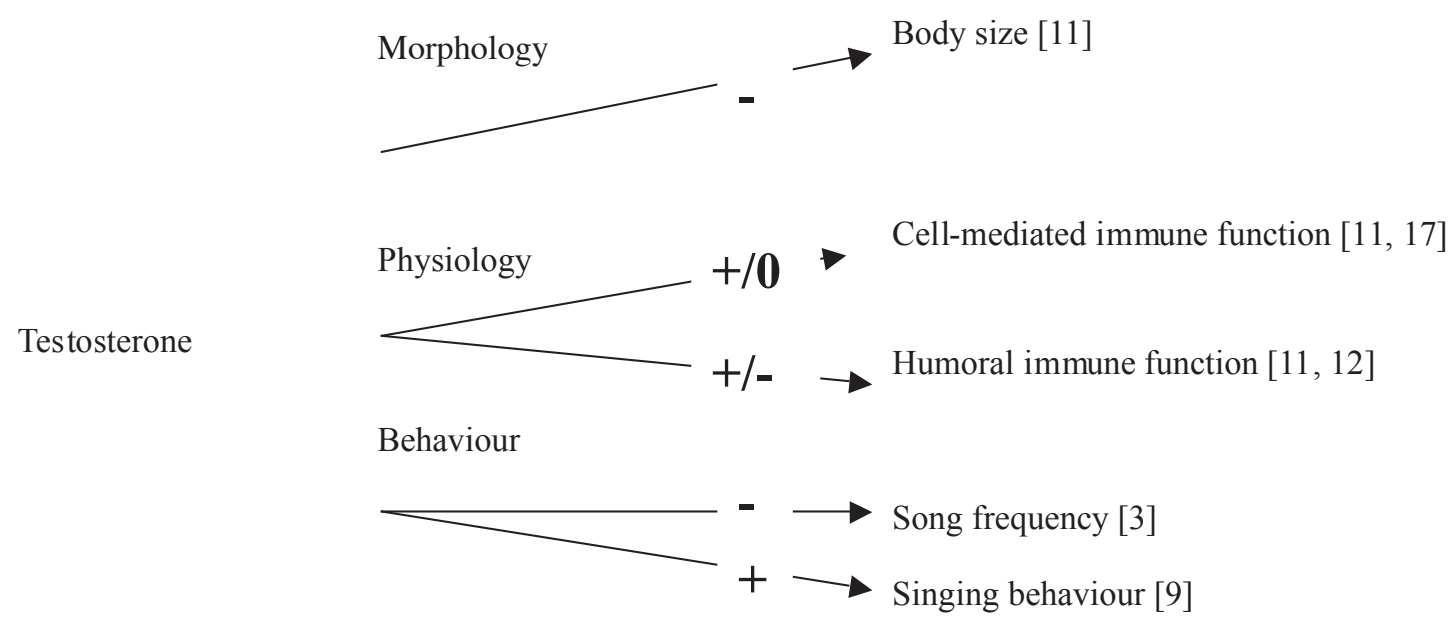

Fig. (3). Summary of the effects of testosterone on zebra finch physiology, morphology and behaviour.

freed resources into dominance behaviours. The link between testosterone and corticosterone might then make sense as a way of modifying the resource distribution between physiological processes according to individual quality or state.

The preceding discussion has been based on results obtained in one species - the house sparrow. However, the results of testosterone manipulations in different species are not always been consistent. For example, testosterone correlates well with corticosterone titres in house sparrows [14, 20] and starlings (Sturnus vulgaris) [47] but not in whitecrowned sparrows (Zonotrichia leucophrys gambelii) [48] or white-plumed honeyeaters (Lichenostomus penicellatus) [49]. Similarly, some studies report that testosterone impairs immune function while others show no significant effect and yet others show a positive effect. Roberts et al. [24] found that if the studies published between 1992 and 2002 were examined then no overall effect of testosterone manipulation on immune function could be discerned. If the linkages created by testosterone between different aspects of an animal's physiology, behaviour and morphology were the result of selection for adaptive functions perhaps it is not surprising that different species reach different adaptive solutions for the patterns of these links, which would depend on the specific demands on their ecology and life history (compare for example the influence of testosterone on behaviour, morphology and physiology in zebra finches (Fig. 3) with those found in house sparrows (Fig. 1)). In addition if testosterone is the hormone that acts to tip the animals between 'harelike' and 'tortoise-like' life-histories, this might mean different things in different species. Perhaps the attempt to produce a synthesis that generalises these effects across taxa is missing informative diversity. Perhaps we should instead be examining the selection pressures that produce hormonal links between aspects of an individual's physiology, behaviour and morphology and how these might differ between taxa.

If the adaptive reason why testosterone influences particular traits is because it tips animals in the direction of fast life-histories, we would expect within a species for testosterone titres to be related to life-history variables. We would, for example, expect to find that adult survival was reduced, age at maturity was reduced and annual fecundity was increased in individuals, which had raised testosterone titres with respect to controls. Experimental investigations such as these would move the emphasis from mechanism to function and may prove a fruitful line of enquiry [50].

\section{ACKNOWLEDGEMENTS}

The genesis of this article occurred after a presentation in Cambridge when Rufus Johnstone raised his concerns about the links produced by testosterone, this article is an attempt to embark upon an answer to his question. Further discussions have been had with many people after presentations in several universities. This paper was initially drafted whilst receiving the hospitality of the Department of Zoology, University of Stellenbosch, many thanks in particular to Mike Cherry for hosting my visit. Thanks to Aldo Poiani and an anonymous referee for useful comments on the manuscript.

\section{REFERENCES}

[1] Buchanan KL, Evans MR, Goldsmith AR, Bryant DM, Rowe LV. Testosterone influences basal metabolic rate in male house sparrows: a new cost of dominance signalling? Proc R Soc Ser B 2001; 268: 1337-44.

[2] Spencer KA, Verhulst S. Delayed behavioral effects of postnatal exposure to corticosterone in the zebra finch (Taeniopygia guttata) Horm Behav 2007; 51: 273-80.

[3] Cynx J, Bean NJ, Rossman I. Testosterone implants alter the frequency range of zebra finch songs. Horm Behav 2005; 47: 446-51.

[4] Loiseau C, Sorci G, Dano S, Chastel O. Effects of experimental increase of corticosterone levels on begging behavior, immunity and parental provisioning rate in house sparrows. Gen Comp Enocrinol 2008; 155: 101-8.

[5] Spencer KA, Buchanan KL, Goldsmith AR, Catchpole CK. Song as an honest signal of developmental stress in the zebra finch (Taeniopygia guttata). Horm Behav 2003; 44: 132-9.

[6] Bokony V, Liker A, Lendvai AZ, Kulcsar A. Risk-taking and survival in the house sparrow Passer domesticus: are plumage ornaments costly? Ibis 2008;150:139-51.

[7] Lofts B, Murton RK, Thearle RJP. Effects of testosterone propinate and gonadotropins on bill pigmentation and testes of house sparrow (Passer domesticus). Gen Comp Endocrinol 1973; 21: 202-9.

[8] Martins TLF, Roberts ML, Giblin I, Huxham R, Evans MR. Speed of exploration and risk-taking behavior are linked to corticosterone titres in zebra finches. Horm Behav 2007; 52: 445-53.

[9] Hill WL, Ballard S, Coyer MJ, Rowley T. The interaction between testosterone and breeding phase on the reproductive behavior and use of space of male zebra finches. Horm Behav 2005; 47: 452-8. 
[10] Roberts ML, Buchanan KL, Bennett ATD, Evans MR. Mate choice in zebra finches: does corticosterone play a role? Anim Behav 2007; 74: 921-9.

[11] Roberts ML, Buchanan KL, Hasselquist D, Evans MR. Effects of testosterone and corticosterone on immunocompetence in the zebra finch. Horm Behav 2007; 51: 126-34.

[12] Roberts ML, Buchanan KL, Hasselquist D, Bennett ATD, Evans MR. Physiological, morphological and behavioural effects of selecting zebra finches for divergent levels of corticosterone. J Exp Biol 2007; 210: 4368-78.

[13] Hodgson ZG, Meddle SL, Roberts ML, et al. Spatial ability is impaired and hippocampal mineralocorticoid receptor mRNA expression reduced in zebra finches (Taeniopygia guttata) selected for acute high corticosterone response to stress. Proc R Soc Ser B 2007; 274: 239-45.

[14] Buchanan KL, Evans MR, Goldsmith AR. Testosterone, dominance signalling and immunosuppression in the house sparrow, Passer domesticus. Behav Ecol Sociobiol 2003; 55: 50-9.

[15] Mazuc J, Chastel O, Sorci G. No evidence for differential maternal allocation to offspring in the house sparrow (Passer domesticus). Behav Ecol 2003; 14: 340-6.

[16] Hegner RE, Wingfield JC. Effects of experimental manipulation of testosterone levels on parental investment and breeding success in male house sparrows. Auk 1987; 104: 462-9.

[17] McGraw KJ, Ardia DR. Do carotenoids buffer testosterone-induced immunosuppression? an experimental test in a colourful songbird. Biol Lett 2007; 3: 375-8.

[18] Poiani A, Goldsmith AR, Evans MR. Ectoparasites of house sparrows (Passer domesticus): an experimental test of the immunocompetence handicap hypothesis and a new model. Behav Ecol Sociobiol 2000; 47: 230-42.

[19] Temple R. The genius of china. $3^{\text {rd }}$. ed; London: Andre Deutsch 2007.

[20] Evans MR, Goldsmith AR, Norris SRA. The effects of testosterone on antibody production and plumage coloration in male house sparrows (Passer domesticus). Behav Ecol Sociobiol 2000; 47: 156-63.

[21] Folstad I, Karter AJ. Parasites, bright males, and the immunocompetence. Am Nat 1992; 139: 603-22.

[22] Gonzalez G, Sorci G, Smith LC, de Lope F. Testosterone and sexual signalling in male house sparrows (Passer domesticus). Behav Ecol Sociobiol 2001; 50: 557-62.

[23] Owens IPF, Short RV. Hormonal basis of sexual dimorphism in birds - implications new theories of sexual selection. Trends Ecol Evol 1995; 10: 44-7.

[24] Roberts ML, Buchanan KL, Evans MR. Testing the immunocompetence handicap hypothesis: a review of the evidence. Anim Behav 2004; 68: 227-39.

[25] Wedekind C, Folstad I. Adaptive or nonadaptive immunosuppression by sex. Am Nat 1994; 143: 936-8.

[26] Hillgarth N, Ramenofsky M, Wingfield JC. Testosterone and sexual selection. Behav Ecol 1996; 8: 108-12.

[27] Wingfield JC. A continuing saga: the role of testosterone in aggression. Horm Behav 2005; 48: 253-5.

[28] Tinbergen N. On aims and methods of ethology. Z Tierpsychol 1963; 20: 410-33

[29] Deviche P, Breuner CW, Orchinik M. Testosterone, corticosterone and photoperiod interact to regulate plasma levels of binding globulin and free steroid hormone in drak-eyed juncos, Junco hyemalis. Gen Comp Endocrinol 2001; 122: 67-77.

[30] Swett MB, Breuner CW. Interaction of testosterone, corticosterone and corticosterone binding globulin in the white-throated sparrow
(Zonotrichia albicollis). Comp Biochem Physiol A 2008; 151: 22631.

[31] Klukowski LA, Cawthorn JM, Ketterson ED, Nolan V. Effects of experimentally elevated testosterone on plasma corticosterone and corticosteroid binding globulin in dark-eyed juncos (Junco hyemalis). Gen Comp Endocrinol 1997; 108: 141-51.

[32] Kam K, Park Y, Cheon M, Son GH, Kim K, Ryu K. Effects of immobilization stress on estrogen-induced surges of luteinising hormone and prolactin in ovariectomised rats. Endocrine 2000; 12: 279-87.

[33] Gould SJ, Lewontin RC. Spandrels of san-marco and the panglossian paradigm - a critique of the adaptationist program. Proc R Soc Ser B 1979; 205: 581-98.

[34] Wingfield JC, Maney DL, Breuner CW, et al. Ecological bases of hormone-behavior interactions: "the emergency life history stage." Am Zool 1998; 38:191-206.

[35] Råberg L, Grahn M, Hasselquist D, Svensson E. On the adaptive significance of stress induced immunosuppression. Proc R Soc Ser B 1998; 265: 1637-41.

[36] Wingfield JC, Hegner RE, Dufty AM, Ball GF. The "challenge hypothesis": theoretical implications for patterns of testosterone secretion, mating systems and breeding strategies. Am Nat 1990; 136: 829-46.

[37] Lynn SE, Hayward LS, Benowitz-Fredericks ZM, Wingfield JC. Behavioural insensitivity to supplementary testosterone during the parental phase in the chestnut-collared longspur Calcarius ornatus. Anim Behav 2002; 63: 795-803.

[38] Lynn SE, Walker BG, Wingfield JC. A phylogentically controlled test of hypotheses for behavioral insensitivity to testosterone in birds. Horm Behav 2005; 47: 170-7.

[39] Van Duyse E, Pinxten R, Eens M. Does testosterone affect the trade-off between investment in sexual/territorial behavior and parental care in male great tits? Behavior 2000; 137: 1503-15

[40] Møller AP. Social control of deception among status signalling house sparrows Passer domesticus. Behav Ecol Sociobiol 1987; 20: 307-11.

[41] Møller AP. Variation in badge size in male house sparrows (passer domesticus): evidence for status signalling. Anim Behav 1987; 35 203-10.

[42] Møller AP. House sparrow, passer domesticus, communal displays Anim Behav 1987; 35: 203-10.

[43] Grafen A. Biological signals as handicaps. J Theor Biol 1990; 144 517-46.

[44] Harvey S, Phillips JG, Rees A, Hall MR. Stress and adrenal function. J Exp Zool 1984; 232: 633-45.

[45] Silverin B. Stress responses in birds. Poult Avian Biol Rev 1998; 9: 153-68.

[46] Buchanan KL. Stress and the evolution of condition-dependent signals. Trends Ecol Evol 2000; 15: 156-60.

[47] Duffy DL, Bentley GE, Drazen DL, Ball GF. Effects of testosterone on cell-mediated and humoral immunity in non-breeding adult starlings. Behav Ecol 2000; 11: 654-62.

[48] Wikelski M, Lynn S, Breuner CW, Wingfield JC, Kenagy GJ. Energy metabolism, testosterone and corticosterone in whitecrowned sparrows. J Comp Physiol 1999; 185: 463-70.

[49] Buttemer WA, Astheimer LB. Testosterone does not affect basal metabolic rate or blood parasite load in captive male white-plumed honey eaters Lichenostomus penicillatus. J Avian Biol 2000; 31: 479-88.

[50] Kempenaers B, Peters A, Faerster K. Sources of individual variation in plasma testosterone levels. Phil Trans R Soc B 2008; 363 : 1711-23.

(c) Matthew R. Evans; Licensee Bentham Open.

This is an open access article licensed under the terms of the Creative Commons Attribution Non-Commercial License (http://creativecommons.org/licenses/ by-nc/3.0/) which permits unrestricted, non-commercial use, distribution and reproduction in any medium, provided the work is properly cited. 